\title{
Retrato de familia
}

A family portrait

Jacqueline Weinstein Levy

Universidad de Chile

jacqueline.wl@gmail.com

Chile

Para mis nietas A. y B., ojalá le den continuidad al largo camino recorrido por nuestra familia que se entronca con la historia de un pueblo milenario.

Sobre la identidad judía...., han dicho:

"Puede que sea algo físico y metafísico a la vez." (Natan Sznaider, 2012)

“Una tradición oculta." (Hannah Arendt, 2007)

\section{RESUMEN}

El tema que abordo es un relato sobre mis antepasados desde el punto de vista de sus procesos migratorios, destacando las áreas geográficas de donde procedieron, en Europa del Este. Como elemento de contexto incorporo el siglo XX en el cual les tocó vivir, cruzado por las guerras mundiales, muy incidentes en sus vidas, en particular la segunda; así como, por el arraigo del proceso de modernización como etapa previa a la globalización, donde se asientan como relevantes los rasgos asociados a estilos de vida propios de lo urbano y cosmopolita. Entre estos procesos se establecen relaciones que se van retroalimentando mutuamente. A partir de este enfoque, sostengo que las acciones y decisiones que fueron tomando mis padres y abuelos en distintas etapas de su vida estuvieron influidas por dichos condicionantes y experiencias, y los hizo proclives a la asimilación.

PALABRAS CLAVES: vapor Wesser, inmigrantes macedónicos, memoria judía, diversidad judía

\section{ABSTRACT}

My ancestors are the subject of this story. I tell it, using as a conductive line their migratory processes from Eastern Europe, the land where they all were coming. As a context for the story I incorporate the 
$20^{\text {th }}$ century and its main events, especially the two world wars that were very influential in their own lives. Also, as the story demanded it, the modernization process as a previous stage to globalization, with their influence over the urban and cosmopolitan ways of life, was taken into account. I believe that the interaction of all these processes, can explain most of the decisions and actions tacken by my ancestors at several stages of their lives and also made them prone to assimilation.

KEYWORDS: Wesser steam. Macedonian immigrants. Jewish memory, Jewish diversity

Mis abuelos fueron personas muy presentes y gravitantes, en mi vida y formación. Se fueron convirtiendo en una especie de prolongación de mis padres, me dieron seguridad, afecto, valores, hogar. Ellos eran judíos, por afirmación, socialización y tradición, sin ser religiosos. Esta condición fue una realidad cotidiana en sus vidas, sustentada en parientes y amigos que siempre eran numerosos, y con quienes a veces hablaban en sus propias lenguas que trajeron de Europa (yidish y ladino). También eran parte de esta clara pertenencia grupal las visitas al templo para algunas festividades, las comidas familiares que eran abundantes en recetas típicas, las conversaciones, recuerdos, olores y sabores. Desde muy pequeña me transmitieron su identidad judía, que la percibí muy vinculada a su condición de migrantes, así como al territorio del cual provenían y a las contingencias históricas que enfrentaron.

No obstante, su presente y futuro estuvieron decididamente en los países de acogida (Argentina y Chile), donde ejercían con responsabilidad sus deberes y derechos ciudadanos. Más adelante en el texto voy a retomar y reflexionar sobre esta materia.

\section{Las pastas en la cocina de calle Marín}

Desde que tengo uso de razón supe que mi abuelo Mauricio Weinstein Chodig venía del pueblo de Smotrich en Ucrania, Rusia (vecino a la frontera con Rumania y Moldavia). En la primera década del siglo XX, con sus padres León y Marta y su hermano Isaac emigró a Chile, afectados por las persecuciones zaristas como tantos otros judíos. Entre mis primeros recuerdos están los paseos dominicales con este abuelo, quién nos venía rigurosamente a buscar con una prima y nos llevaba a distintos parques de barrio del Santiago de los cincuenta; cómo me gustaba estar cerca de él. 
Su mujer, mi abuela Anita, contaba que cuando mi abuelo quiso casarse recurre a conocidos que tenía en Argentina, que es donde se quedaban la mayoría de los judíos que llegaron de Rusia, y así se produce este matrimonio entre ellos que fue "arreglado" pero muy feliz. Se establecen en Chile, aunque mi papá Jorge Weinstein Winocur nace en Buenos Aires donde la abuela se traslada para tenerlo cerca de sus propios padres. De esta forma él adquiere la nacionalidad argentina, como también lo era su mamá, que fue la única de mis abuelos que nació en América. (Se anexa al final del texto el árbol de familia).

En la Figura 1 presento a mis abuelos Anita y Mauricio con su registro matrimonial. Ella tiene un look "charlestoniano" muy de la época (los veinte), la foto está inserta en el pasaporte con el cual viajó a Chile recién casada. Él aparece mucho mayor, descendiendo de un avión en Madrid, lo que lo representa muy bien porque fue un viajero empedernido. En la otra foto tiene 68 años, era el hombre más buenmozo y adorable que he conocido.

En la Figura 2 está inserta la copia certificada del año 1948, de la carta de nacionalidad del abuelo Mauricio, suscrita por el Presidente Barros Luco y su Ministro del Interior Tocornal en 1912, por tanto, obtenida muy pocos años luego de su llegada a Chile. Creo que este acto le cambió la vida -no más trasplantado-, siendo poco habitual entre los inmigrantes de la época tramitarlo con tal prontitud. Con razón cuando aparecí en la familia, 40 años después, siempre me pareció un chileno al ciento por ciento (aunque hablaba con un leve acento). 


\section{Figura 1}

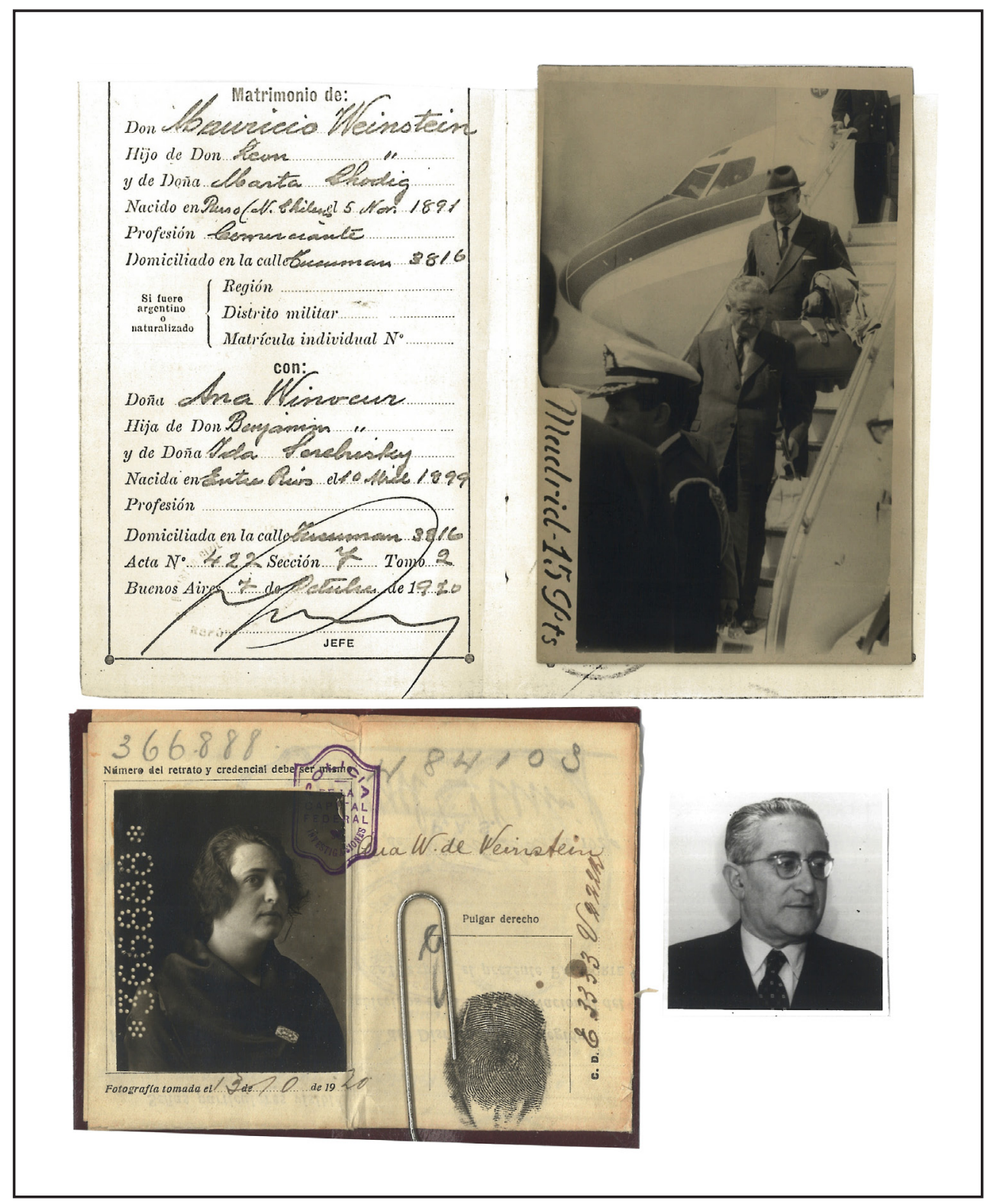


Figura 2



No conocí a los bisabuelos que fueron los padres de mi abuela Anita, pero tuve la suerte de reconstituir bastante pormenorizadamente -a partir de un valioso material que me envío una pariente de 
Buenos Aires (Mendelson et. al., 1939)-, la inmigración a la Argentina del bisabuelo Benjamín Winocur (originalmente Vinokur). Historia plena de vicisitudes propias de estos procesos. Proveniente de la ciudad de Kamenetz, capital de la región de Podolia en el suroeste de Ucrania (cercana por lo demás, al pueblo de la familia de mi abuelo paterno), junto con sus padres, mis tatarabuelos Jacobo (lankel) y Rosa (Dwosa) -ambos nacidos en 1841-y cinco hermanos, fueron parte del primer grupo de colonizadores judíos (136 familias, más de 800 personas) que recibió Argentina, Ilegando a Buenos Aires el 14 de agosto de 1889 en el vapor Wesser que tomaron en Bremen, Alemania. En su recorrido por tierra desde su lugar de origen, en Rusia, hasta el puerto de embarque, estas familias sufrieron varios inconvenientes, incluso penurias, que ya arrastraban por los asaltos de la monarquía rusa (los "progroms" antijudíos). Lamentablemente éstas continuarían en Argentina, donde al llegar constataron que los campos que supuestamente habían adquirido por intermedio del cónsul argentino en París, estaban ocupados hacía tiempo. No obstante siguieron a su destino instalándose en el sector de Palacios en la provincia de Santa Fe, donde se alojaron en galpones y vagones de carga, en pésimas condiciones sanitarias lo que unido a la falta de alimentos propagó una epidemia de tifus, falleciendo decenas de los niños del grupo. De alguna manera malamente subsistieron, pero muy pronto se produjo una dispersión de las familias por las poblaciones de los contornos. La verdadera hazaña sufrida por ellos hizo eco en el Barón de Hirsch, filántropo judío alemán, quien funda la Jewish Colonization Association (JCA) con la finalidad de establecer en Argentina (y otros países de América) en calidad de agricultores, a judíos europeos pobres y afectados por continuos actos de violencia. De esta forma, en 1891 adquirió los primeros campos precisamente en el sector de Palacios, donde asentó en lo que se llamó la colonia de Moisesville a un grupo importante de los judíos del vapor Wesser. Luego continúo comprando tierras en distintas provincias argentinas, entre ellas, la de Entre Ríos.

No tengo antecedentes precisos de lo qué pasó con la familia Winocur, sólo que 10 años más tarde nació mi abuela Anita en Villaguay, Entre Ríos, de donde deduzco que mi bisabuelo con su mujer Ida se asentaron en alguna de las colonias agrícolas que estableció la JCA en esta provincia. Tengo testimonio de que fue un tiempo agricultor, para luego trasladarse a Buenos Aires con su familia, a principios del siglo pasado, como lo hicieron finalmente la mayoría de Ios colonos; aunque una parte pequeña de la familia permaneció en Rosario, provincia de Santa Fe. Un hecho a destacar es que cuando inscribieron el nacimiento de mi abuela en el 
registro civil, sus padres se declararon ambos de religión protestante. ¿Tan vulnerables se seguían sintiendo? En este punto, me hace mucho sentido la "tradición oculta" a la que se refiere Hannah Arendt (2007), en sus Ilamados escritos judíos. Reconocida e influyente intelectual alemana-americana del siglo XX, ese término lo introduce esta autora cuando analiza el proceso de emancipación de los judíos que promovió el Estado alemán en el siglo XIX. La opción que ellos fueron tomando de insertarse en el espacio público, fue a costa de retrotraer su propia identidad al ámbito de la vida privada. El dilema entonces, era ser judío o ser moderno (Martínez Pardo, 2009).

Mi abuela Anita narraba que provenían de una familia culta y educada, y dada las condiciones y las restricciones en que vivían los judíos en Rusia en esos tiempos, me doy cuenta que eso sólo pudo darse en un ambiente de estudios del judaísmo en sus propios centros o escuelas, lo que estaba unido al culto religioso. Esto lo corrobora el que su tío León Winocur (hermano de su padre) fue autor de un diccionario hebreo-castellano que se encuentra en bibliotecas judías; y, asimismo, fue director de la primera Yeshiva para la enseñanza del judaísmo en la Argentina, que se funda en 1911 en la colonia Fainberg, en Entre Ríos. La importancia del estudio como medio de superación y crecimiento fue algo que me transmitieron mis abuelos y mis padres desde que tengo uso de la razón.

La Figura 3 es una composición hecha a partir de tres momentos distintos en el tiempo, relacionados con mi padre. La base es el cable telegráfico -que fue guardado con mucho celo por la familia- enviado por el bisabuelo Benjamín a su yerno, mi abuelo Mauricio, desde Buenos Aires a Santiago anunciando el nacimiento de mi papá en 1921. Sobre escrito con posterioridad en el mismo documento, fue transcrita su fecha de nacimiento en el calendario hebreo (año 5710, 23 del mes de Tamuz) y se registra también en hebreo la palabra "parashat pinjas", que es una porción de la lectura semanal de la Torá en la sinagoga que se realiza en fechas próximas al mes de Tamuz. Esta inscripción me resulta muy coherente con lo que he narrado sobre la religiosidad de estos ancestros, la familia Winocur. La foto en la figura la inserté en el cable porque aparece mi papá de niño (el de la izquierda, con su hermano y primos de la Argentina), junto al primer auto que tuvieron sus padres. 
Figura 3

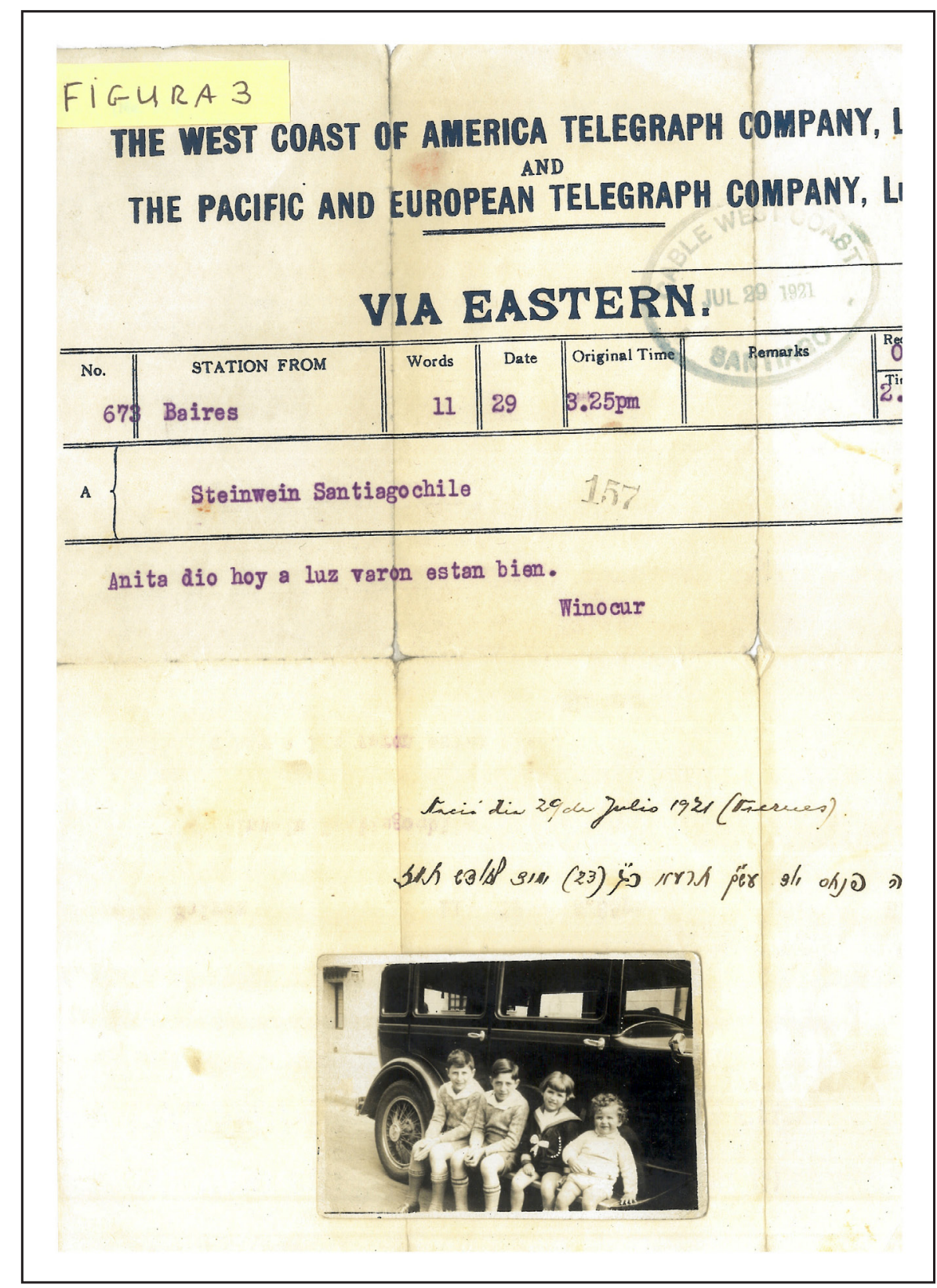

De mi bisabuela Ida Serebrisky, esposa de Benjamín, la única información que dispongo es el pasaporte inserto en las Figuras 4a, 4b y 4c. Así me enteré de que nació en Kichinev, actualmente Chisinau, capital de Moldavia, que en ese momento era la región de Bessarabia bajo ocupación rusa, hasta 1859 dominada por el imperio otomano. En una zona de alta conflictividad por ser corredor entre oriente y occidente (como el resto de esa área geográfica), Kichinev fue fundada en 1466, y desde temprano se radicaron ahí judíos europeos. Era parte de un principado medioeval del alto Danubio conformado por las regiones de Bessarabia y Bucovine 
(esta última actualmente en Rumania), cuyo origen se remonta a la antigua Dacia (provincia del imperio romano). En el siglo XX, Bessarabia fue una república socialista soviética (ex URSS), hasta su independencia como Moldavia recién en 1991. Muchas familias judías emigraron de esta región rusa a la provincia argentina de Entre Ríos en la última década del siglo XIX, con la finalidad de instalarse en las colonias agrícolas adquiridas por el Barón Hirsch. Claramente entre ellas estuvo la de esta bisabuela.

Figura 4a

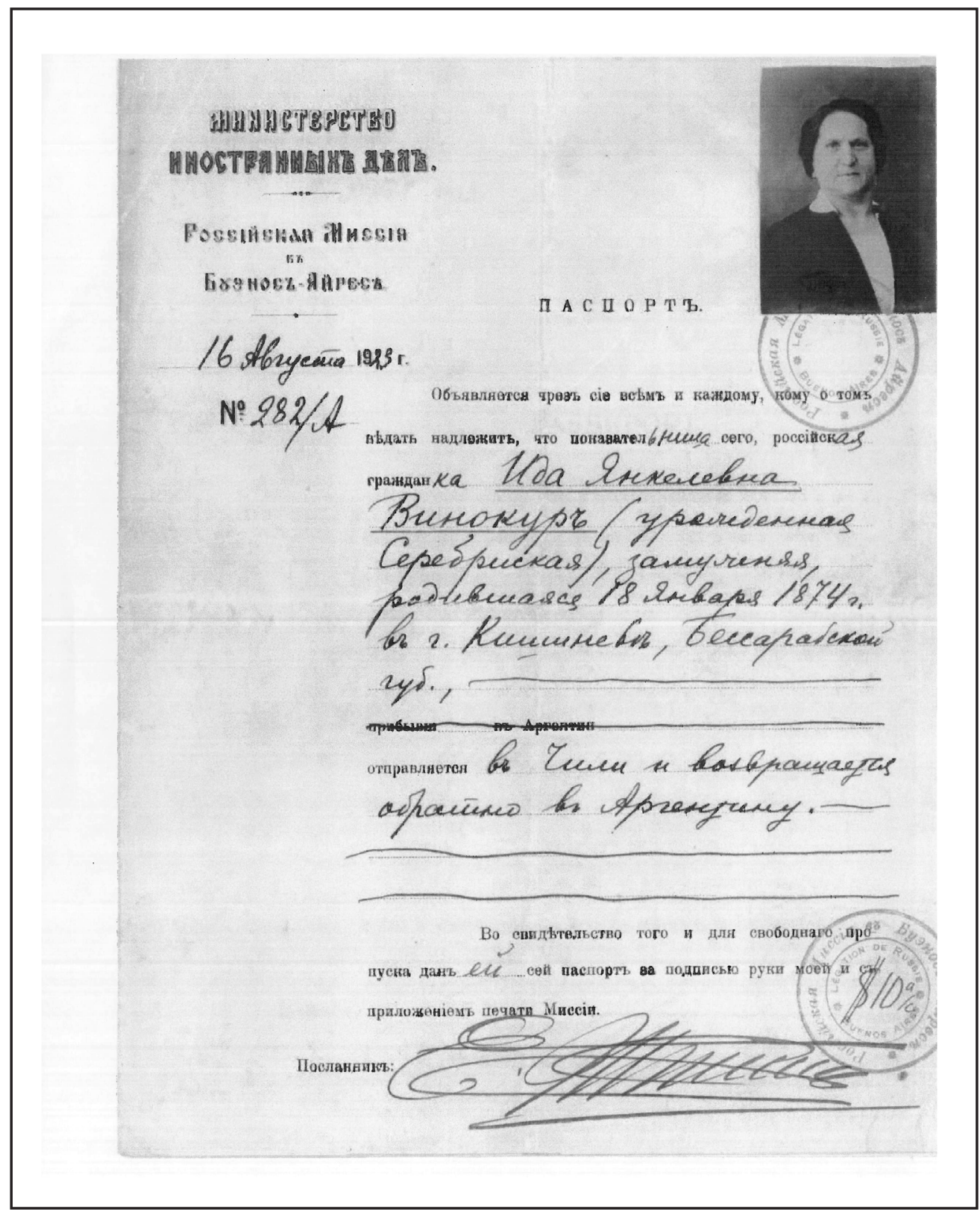




\section{Figura 4b}

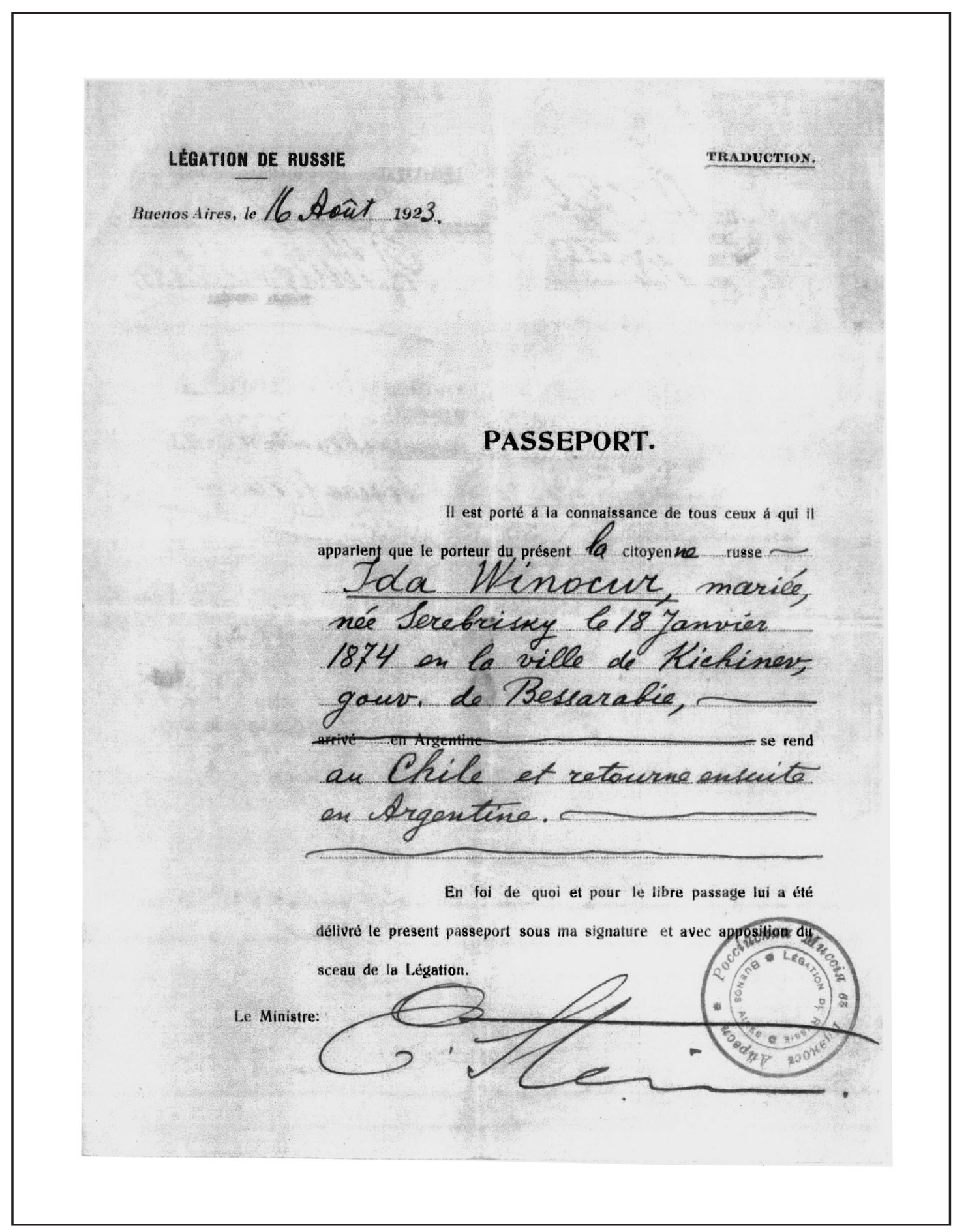


Figura 4c

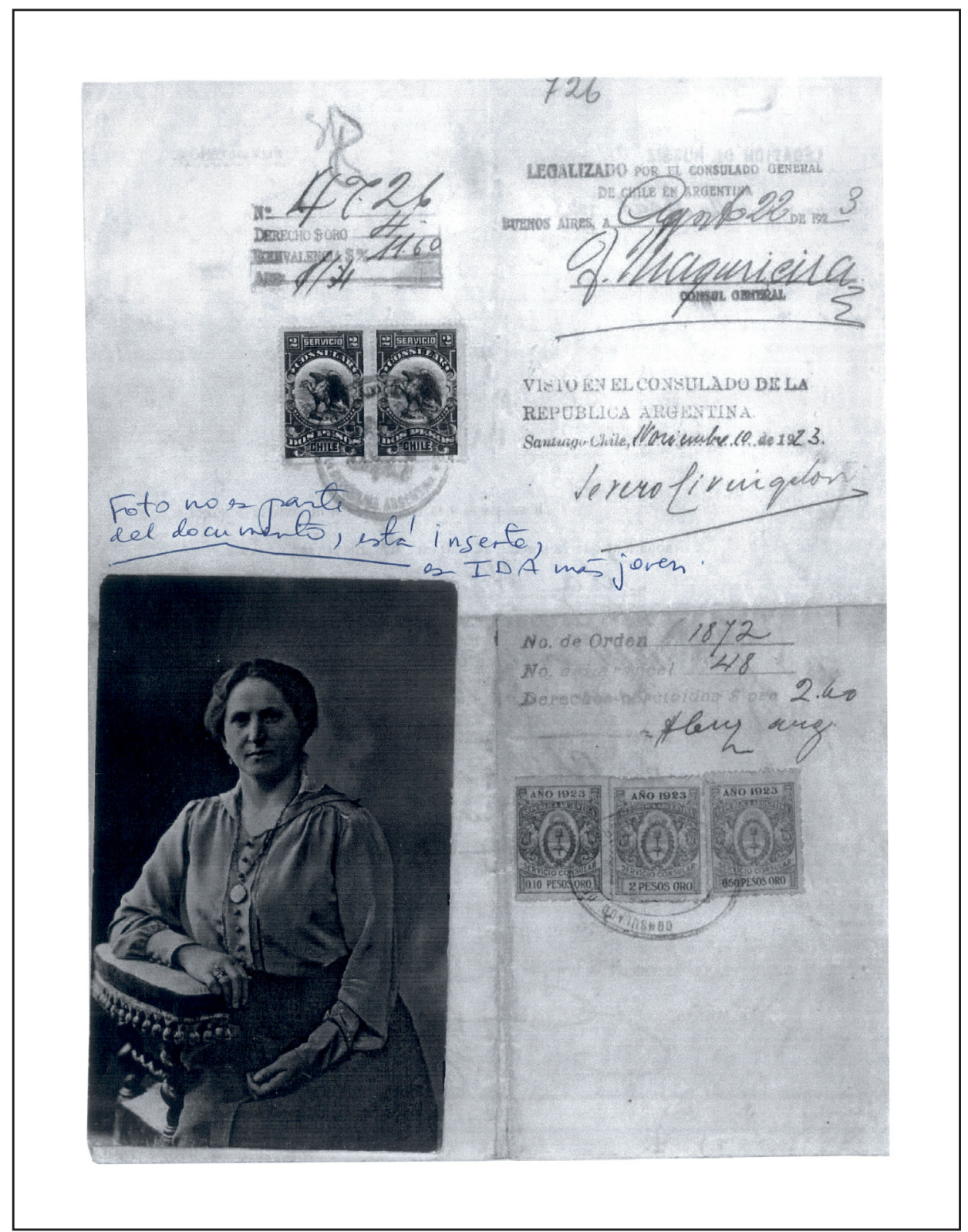

El pasaporte que exhibo de esta bisabuela está en ruso, con traducción al francés y sellos legales, emitido en 1923 por la delegación de Rusia (República Socialista Soviética) en Buenos Aires, con la sola finalidad de viajar a Chile donde residía su hija Anita (mi abuela) y familia. Para esa fecha Ida residía en Argentina estimo que unos 30 años, pero seguía teniendo su nacionalidad de origen, lo que denota un patrón de inserción distinto al de mi abuelo Mauricio según lo relaté. En este documento también encontré inserto, al final, una foto de ella más joven, donde se la ve sobria y elegante a la vez. Es muy valioso porque es el único registro que dispongo de un bisabuelo. 
Así como mis abuelos fueron trascendentes en mi vida también percibí que los suyos lo fueron para mis padres. El ejercicio de recuperar esta cadena genealógica lo inicié luego de la muerte de mis padres, en que el vacío que dejaron me impulsó a buscar mis raíces y a conectarme con mi identidad judía nuevamente, que aunque nunca la perdí estaba subsumida por otros eventos de mi vida. Ha sido parte del proceso de aceptar la ausencia de ellos, y un imperativo para con mis nietas de no desvincularlas del pasado familiar. Pienso que por este camino podrían llegar a la historia de nuestro pueblo y, tal vez, en algún momento sentirse parte de él. Porque, ¿no es que la identidad judía consiste esencialmente en recordar, en recibir y transmitir como un mandato bíblico? (Yerushalmi, 2002; Massmann, 2005; Campos, 2008).

Recuerdo que mi abuela paterna y su familia, le decían "perramo" a los impermeables, piezas que no podían faltar en los hogares y eran usados con mucha frecuencia. Nunca entendí por qué ese apelativo, lo di como un hecho. Recién este año 2012 le encuentro el sentido, a raíz de una visita a Buenos Aires donde soy guiada por una amiga a la centenaria tienda Perramus en el barrio Villa Crespo -aquí tradicionalmente vivieron familias judías-, la cual está especializada en esta prenda de vestir y aún mantiene el prestigio de su marca.

\section{La casa de Av. del Bosque}

En contraste con mi familia paterna tan arraigada en la tradición ashkenazi centro-europea, mi familia materna Levy Camhi son sefaradíes, es decir judeo-españoles. No obstante que la expulsión de los judíos de España se dio en el siglo XV, 400 años después mis antepasados seguían hablando el idioma ladino que caracterizó a este grupo. Provenían de la importante ciudad de Monastir que estuvo bajo dominio turco durante muchos siglos (imperio otomano), hoy día llamada Bitola en el estado de Macedonia. Su proceso migratorio fue inverso al de mis otros bisabuelos, ya que en este caso los pioneros en llegar a Chile fueron los hijos mayores de mis bisabuelos, primero Samuel y luego Jaime Levy, mi abuelo, este último hacia 1910 y con menos de 20 años. Se radicaron en Temuco, que se estaba desarrollando como ciudad recién desde fines del siglo XIX, y que en las primeras décadas del 
siglo $\mathrm{XX}$ recibió a numerosas familias originarias de Monastir, en un proceso migratorio que ha sido objeto de estudio en Chile (Matus, 1993 y Cohen, 2002).

Primero como vendedores ambulantes y feriantes, de la nada mi abuelo y su hermano van progresando económicamente creando establecimientos comerciales propios que derivarán en una sociedad exportadora de productos agrícolas que les dio sustento a ellos y sus familias toda su vida, aunque con muchos avatares (en Temuco y después en Santiago). También ellos jugaron un rol preponderante en el desarrollo de la colectividad judía creando y participando en varias organizaciones (centros comunitarios, asociaciones de solidaridad, sinagogas, escuelas, cementerios). Aunque sus raíces judías estaban claras y seguían las tradiciones, durante mucho tiempo se denominaron sólo macedonios antes de reconocerse abiertamente como judíos, lo que fue habitual en estos inmigrantes (Matus, 1993). Nuevamente surge la "tradición oculta" en mis antepasados.

Entre las familias que Ilegaron a Temuco estaba la de mi abuela materna, Matilde Camhi Baruch también de Monastir, de cuyos antepasados no tengo mayor información. Su papá, Salvador Camhi, había llegado primero a Argentina alrededor de 1911 y después emigró a Chile radicándose en Temuco. Su mujer, mi bisabuela Esther Baruch pudo salir de Monastir unos años más tarde con sus cinco hijos, entre los cuales estaba la abuela Matilde. Ella fue una señora bien de avanzada para su época, eximia cocinera de elegante vestir y buen gusto que acogió y educó en su casa interminablemente a hermanos, cuñados y sobrinos. Algunos de ellos se transformaron después en profesionales y fueron referentes para la familia. Gracias a ella y mi abuelo disfruté durante muchos años de espléndidos veraneos en Viña del Mar cuando era niña y adolescente, en su departamento de 4 poniente con 1 norte. El hermano menor de mi abuela, Enrique, de profesión arquitecto, en el año 1932 acondicionó como sinagoga un edificio multiuso que había inaugurado la comunidad temucana de Monastir unos años antes. Su proyecto ha sido destacado por su analogía con sinagogas tradicionales sefaradíes de la Europa medieval y por su sencillez. (Cohen, 2002). 
En la Figura 5 incluyo el certificado de matrimonio de mis abuelos Jaime y Matilde, año 1920. En la foto que es de varias décadas después, lucen informales, es posible que se encuentren en la entrada del Estadio Israelita donde fueron socios, cuya construcción data de fines de los años cincuenta del siglo pasado. Como pareja proyectan una imagen de solidez y seguridad, eran magníficas personas y juntos armaron una familia muy grande. Lamentablemente no mantengo más documentación sobre ellos, posiblemente quedaron en poder de los hermanos de mi mamá, fueron varios y todos fallecidos.

\section{Figura 5}

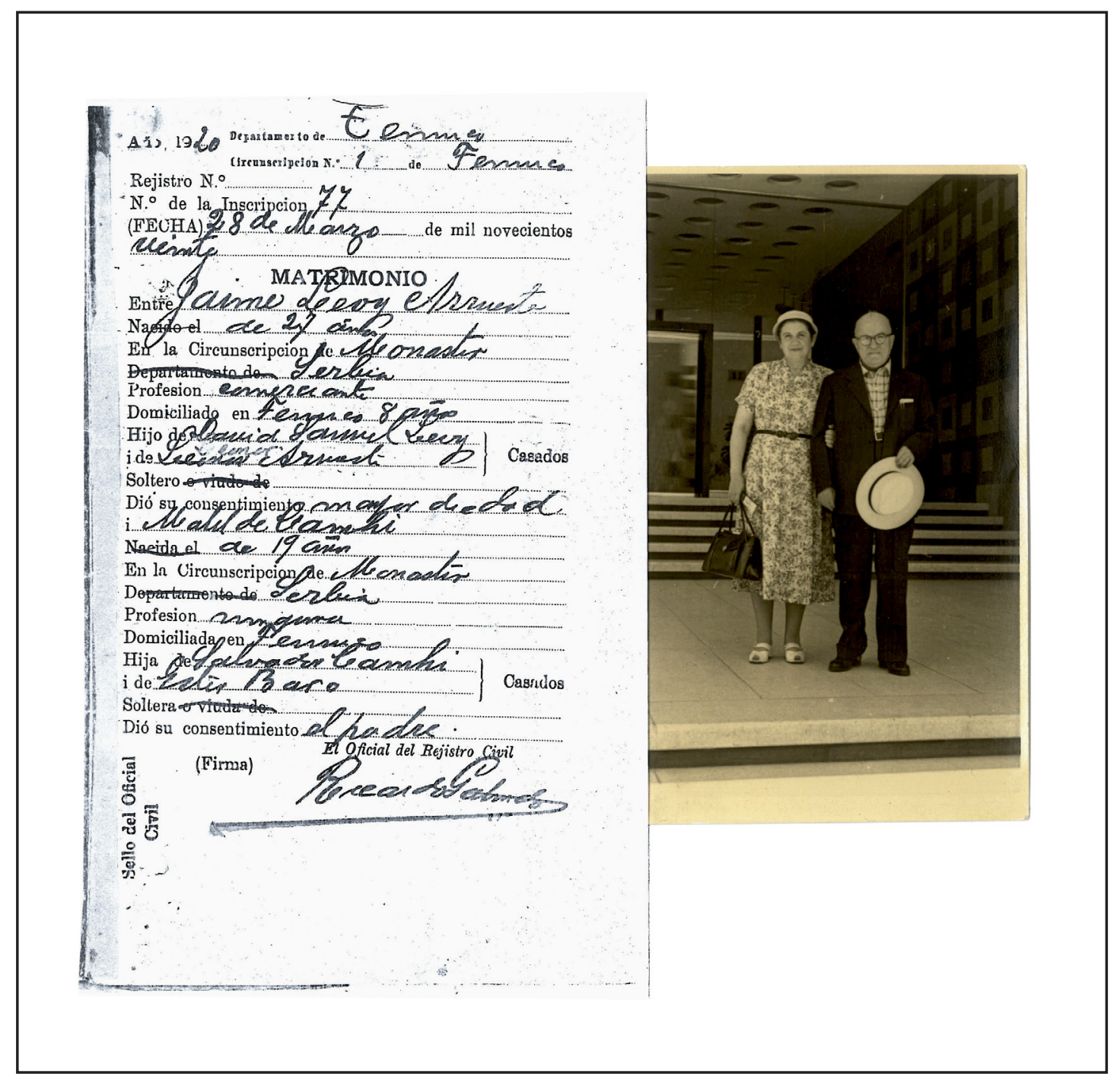


Recién 25 años después de su llegada, los dos hermanos Levy asentados en Temuco pudieron reunirse en Chile con sus padres, mis bisabuelos David Levy Calderón y Leonor (Luna) Arueste, y otros hermanos. ¡Qué dolorosa debe haber sido para ellos esta separación! En particular cuando la situación de la familia que había quedado en Monastir fue muy lamentosa, primero afectada por las Guerras Balcánicas entre 1912-14, y luego por la Primera Guerra Mundial. De hecho, en 1917 la ciudad fue bombardeada por los alemanes por lo que la familia debió abandonarla perdiendo todos sus bienes y el negocio de telas que le daba sustento. Se trasladaron a Salónica en Grecia, y luego a Temuco en 1923. Quedó en Monastir una hermana con su familia, quienes en 1943 junto a 3.270 judíos fueron deportados y asesinados por los nazis en el campo de concentración de Treblinka. ¡Qué tragedia para mis abuelos y qué secreto mejor guardado en la familia, del cual me enteré más de 50 años después cuando mis padres y abuelos habían fallecido! Esto me marcó tremendamente y fue también una de las razones que me llevó a conectarme con mis raíces e investigar, así como documentarme casi con obsesividad sobre la SHOA y peregrinar a los campos de concentración de Aushwitz y Birkenau, en Polonia en 1999.

Recuerdo a mi abuelo Jaime sentado a los pies de mi cama, yo convaleciente de una larga enfermedad con nueve años, contándome interminables historias de su vida y antepasados. Qué esfuerzo de transmisión y qué escasa recepción de mi parte, oportunidad desperdiciada. Recuerdo a mi padre narrándome su experiencia de ser judío durante los años de la II Guerra Mundial cuando era un estudiante universitario y sabía de la tragedia de su pueblo; de la hostilidad que lo afectó y su impotencia frente a ella. El trauma que representaría el Holocausto para el pueblo judío recién comenzaba en ese momento. ¿Se sintió extranjero, me pregunto, a pesar de los esfuerzos hechos por sus propios padres para superar esta condición que fue atávica en la diáspora judía?

No cabe duda que mis abuelos buscaron por todos los medios posibles insertarse en igualdad de condiciones en el país que los acogió como inmigrantes, les dio seguridad e inclusión, en oposición a lo que fue su experiencia como europeos. La visión del mundo que ellos me transmitieron queda muy bien reflejada en el testimonio de mi tío abuelo Teodoro Levy que recoge el profesor Matus en su libro Tradición y Adaptación: Vivencias de los Sefaradíes en Chile (1993), en particular el desapego por lo religioso, la cercanía a la Masonería y el Par- 
tido Radical, el interés por la tarea pública. En la medida que se fueron asimilando fueron abrazando el laicismo, pero se mantuvieron lo suficientemente apegados a las costumbres como para que la identidad judía no fuese anulada. Como argumenta el mismo autor en su libro recién citado, los inmigrantes que Ilegaron a Chile traían consigo una práctica ancestral del judaísmo ejercitada en sus lugares de residencia -profundamente arraigada en sus raíces-, y en ellos era habitual intentar armonizarla con lo que les resultaba ajeno. Sin duda mis antepasados se vieron continuamente confrontados a este proceso, cambiando a lo largo de su historia de países y nacionalidades, pero sin perder la pertenencia a su propio pueblo.

A pesar de todo tipo de avatares esta continuidad cultural (que desde mi punto de vista, controversial, puede o no incluir el culto religioso) ha permanecido hasta mi generación, aunque la gran interrogante es si mis nietos llegarán a ser portadores de ella o serán finalmente completamente absorbidos. Esa "práctica ancestral" del judaísmo que con heterodoxia igual la observé claramente en mis abuelos, se debilitó con mis padres y puede llegar finalmente a desaparecer. No obstante sí debo notar que un sobrino mío, actualmente rabino de una comunidad ortodoxa en Santiago, ha retomado la posta pero percibo que su opción obedece a otro tipo de procesos que escapan a esta narración.

Cuando tenía ocho años viví un tiempo en la casa de mis abuelos maternos. Estando ahí, bajo el segundo Gobierno del Presidente Ibáñez del Campo, el país y sobre todo la capital, atravesó por momentos de gran violencia fruto de una huelga general que derivo en declaración de Estado de Sitio. Los militares patrullaron las calles y mataron a personas, entre ellos un amigo americano de la familia que quebrantó el toque de queda. Todo ello nos provocó gran aflicción, intento salir a la calle y evoco el miedo de mi mamá cerrando con llave el portón de entrada a la casa conminándome a no hacerlo por ningún motivo. Sensación de encierro y de que pasaba algo malo. Al respecto, en su testimonio ya citado mi tío Teodoro Levy dice que le extrañó mucho que los radicales decidieran votar por Ibáñez en su segundo período presidencial, "por muy desengañados que estuvieran".

De esa época, recupero también la tristeza que afectó a mi familia cuando muere de cáncer el cuñado de mi mamá y percibo el desamparo de mi tía viuda y sus dos hijos. Todavía más chica, casi como primer recuerdo, mi asombro y placer al escuchar notas de música, sonidos nuevos que salen del cuarteto de cuerdas del cual mi padre fue primer violín y que me acom- 
pañaron hasta que abandoné ese útero que fue la casa de mis papás. El compromiso político (pasado), y la pasión por la música clásica (siempre), presentes en mi vida, se entroncan con estos recuerdos.

\section{RECAPITULACION SOBRE GEOGRAFIA}

\section{Ucrania y Moldavia}

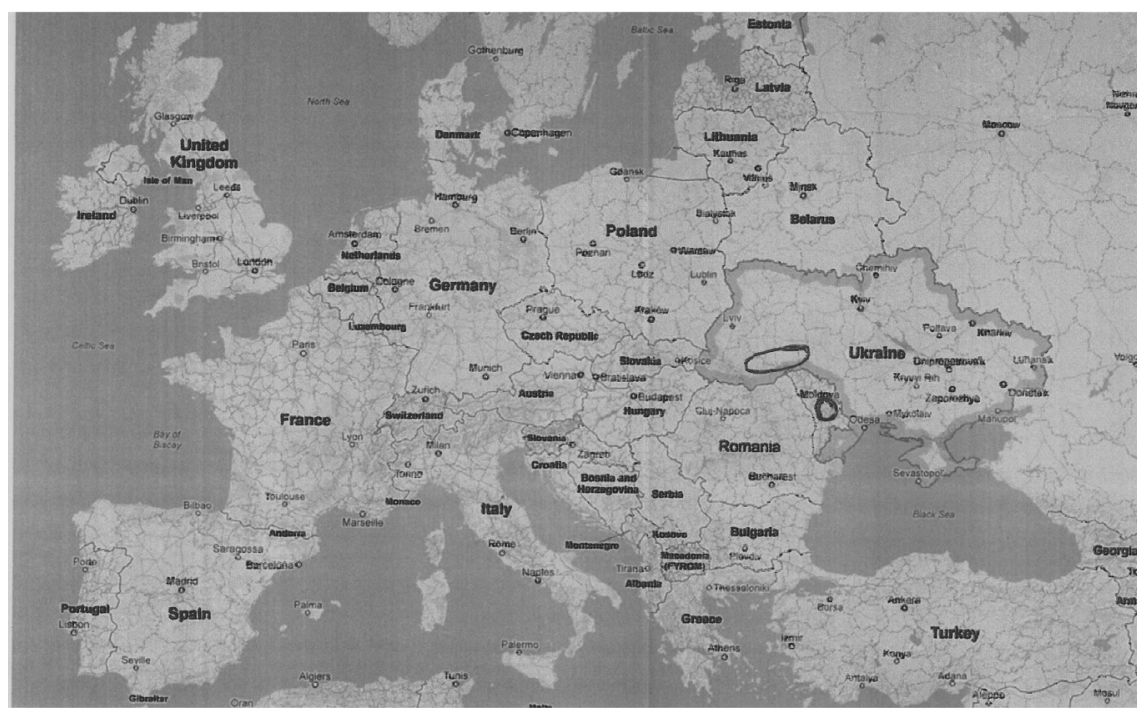

Macedonia

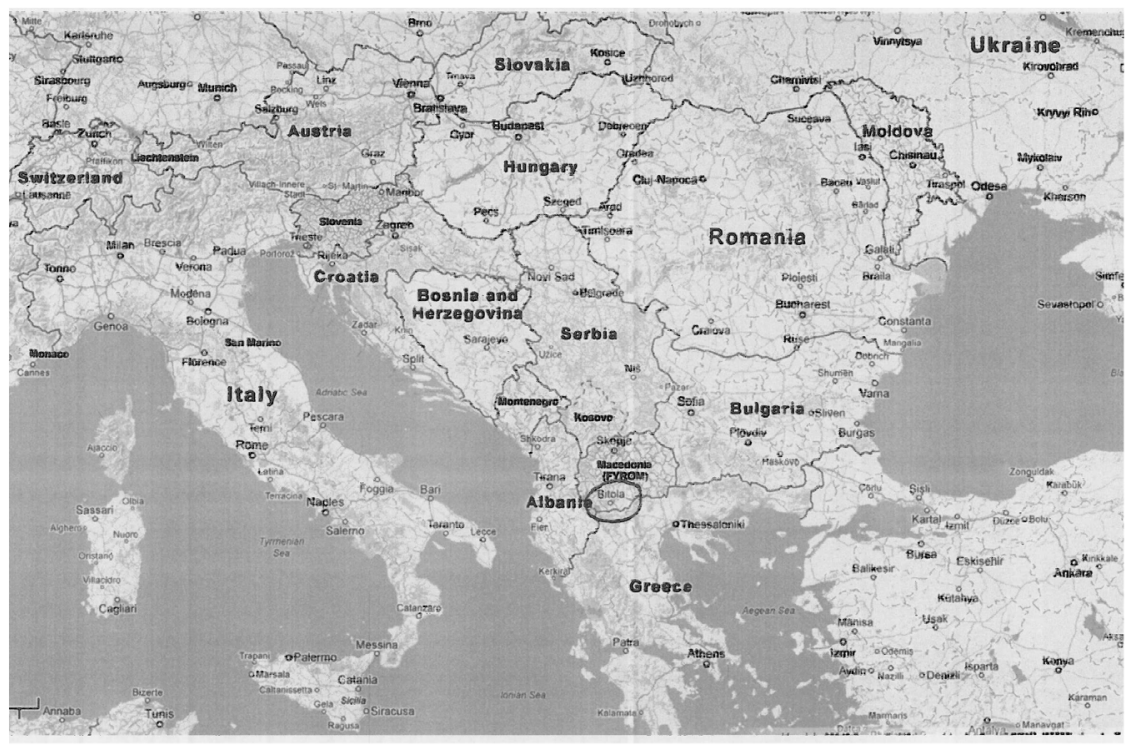


Mis antepasados provinieron, todos ellos, de zonas de frontera sujetas a múltiples cambios de identidad geopolítica y casi permanente conflictividad. Recapitulando, y por el lado paterno, la región de Podolia, hoy integrada a Ucrania, fue parte de la Polonia imperial hasta el siglo XVIII cuando fue conquistada por la monarquía rusa. Después de la revolución de octubre 1917, Ucrania se convirtió en una república socialista soviética hasta 1990 en que se independizó como país. Los judíos que ahí se asentaron se remontan a la época tardomedioeval, como parte de procesos migratorios que se dirigieron a Polonia y más al este europeo, cuyo origen se traza principalmente en el valle del Rhin, en Alemania, donde tendieron a concentrarse importantes poblaciones de la diáspora, principalmente hacia el siglo X. La fuga hacia el este fue la respuesta a actos de violencia que los afectaron fruto de sucesivas expulsiones y el proceso de las Cruzadas. Por su parte, la región de Bessarabia (hoy Moldavia) -de donde procede una de las bisabuelas paternas- siempre fue zona de disputa entre el imperio otomano y el ruso.

Por el lado materno, la península de los Balcanes fue tradicionalmente objeto de disputas entre los imperios aledaños, en particular entre el austro-húngaro y el otomano y, al interior de ella, la región de Macedonia de donde provenían los abuelos y sus antepasados estuvo bajo amenaza de sus países vecinos y, finalmente, dividida entre Bulgaria, Grecia y Serbia como resultado de las Guerras Balcánicas de comienzos del siglo XX. Tampoco es casualidad que el estallido de la I Guerra Mundial se gatille a partir de un magnicidio que acontece en la ciudad de Sarajevo que está en la misma zona. Terminado este conflicto, Macedonia se integró al Reino de Yugoslavia, en 1918, el cual derivó en república socialista después de la I/ Guerra Mundial. Recién en 1991 obtuvo su independencia como país.

Pormenorizo estos acontecimientos porque sin duda esta inestabilidad geopolítica afectó a mis antepasados, más allá de sus particularidades por ser parte de un pueblo de suyo trashumante y objeto de discriminación. A partir de lo cual sostengo que las acciones y decisiones que fueron tomando desde que se radicaron en Chile estuvieron influidas por dicha condición. El profesor Sznaider (2012), a propósito del proceso de emancipación que experimentaron los judios europeos en el siglo XIX, se refiere a la tensión que los cruzó entre ser diferentes y ser iguales, fruto de que, no obstante ser parte de una comunidad fuertemente cerrada y no renunciar a ella, aspiraban a la ciudadanía universal. Yo creo que 
estos sentimientos estuvieron presentes en mis abuelos, y condicionados por su experiencia de vida, fueron optando finalmente por la asimilación como estilo de vida preferente que se acentuará todavía más con mis padres.

\section{La plaza de calle Pocuro}

Mi mamá Luna Levy Camhi nació en Temuco, el 22 de febrero 1927; a los pocos años se radicó en Santiago con su familia. Mi papá Jorge Weinstein Winocur lo hizo en Buenos Aires, el 29 de julio 1921. Este nacimiento en tierra argentina no fue circunstancial para él que siempre se sintió $1 / 3$ argentino y $2 / 3$ chileno, y ello tuvo significación en su vida.

Mario fue el único hermano de mi papá casado con Lea Talesnik. Mi mamá tuvo cuatro: David, León, Herbert (Tato) y Ester (Teté).

En la Figura 6 están mis padres poco antes de conocerse y a una edad muy similar (18 y 16 años, respectivamente), acompañados de su futura tarjeta de visita matrimonial. La foto de ella está inserta en una cédula de identidad, la de él en la libreta de enrolamiento argentina, nacionalidad que siempre conservó junto con la chilena.

Mis jóvenes padres compartieron un pasaporte conjunto el año 1962 (Figura 7), como se observa emitido a nombre de él y ella como su cónyuge acompañante -impensable hoy día, en que la mujer ha ido adquiriendo plenas capacidades legales fruto de un proceso arduo de lucha por la equidad de género. En la figura también incluyo la participación de su compromiso matrimonial por parte de mis abuelos, de agosto 1946. 
Figura 6

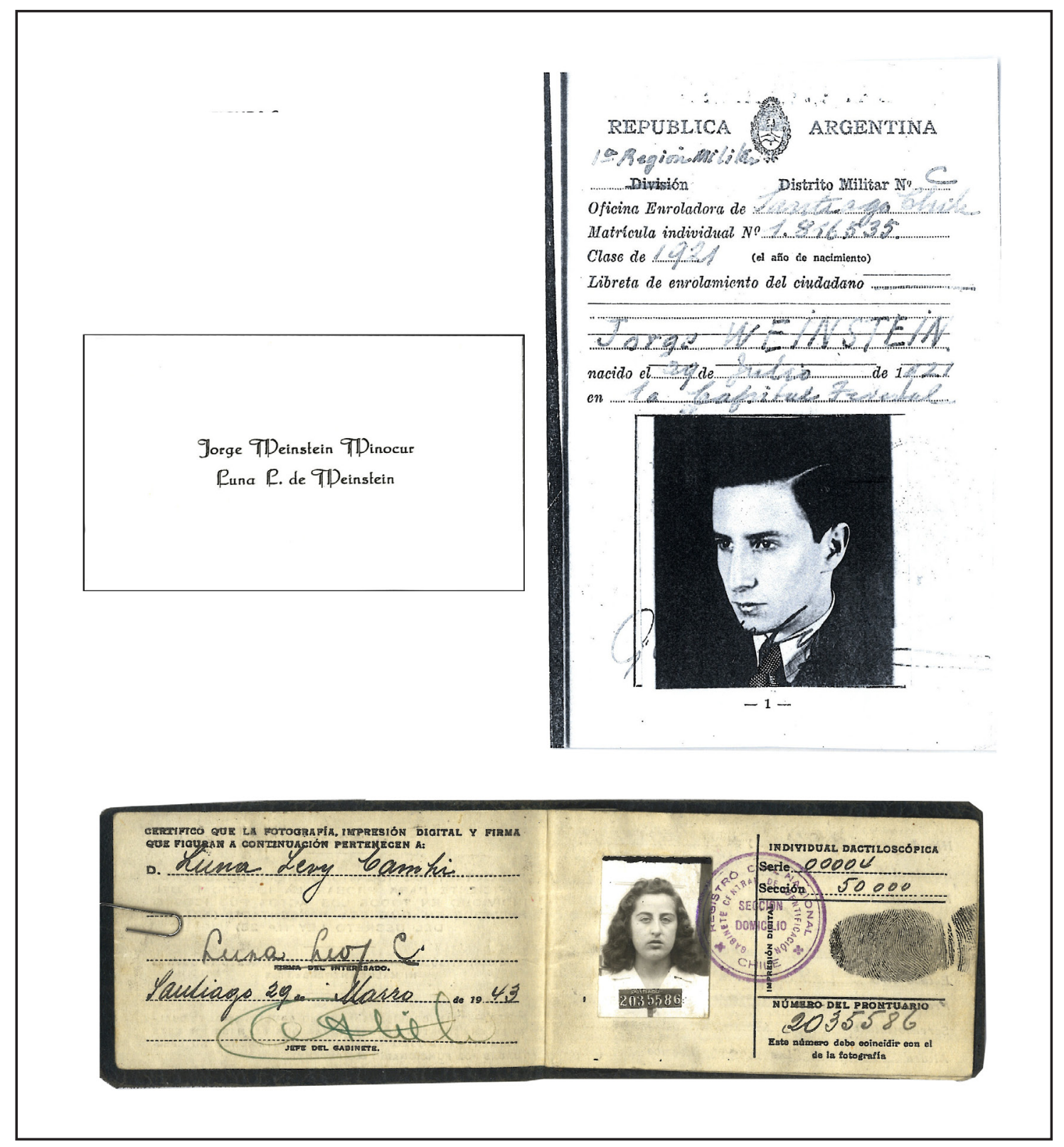


Figura 7

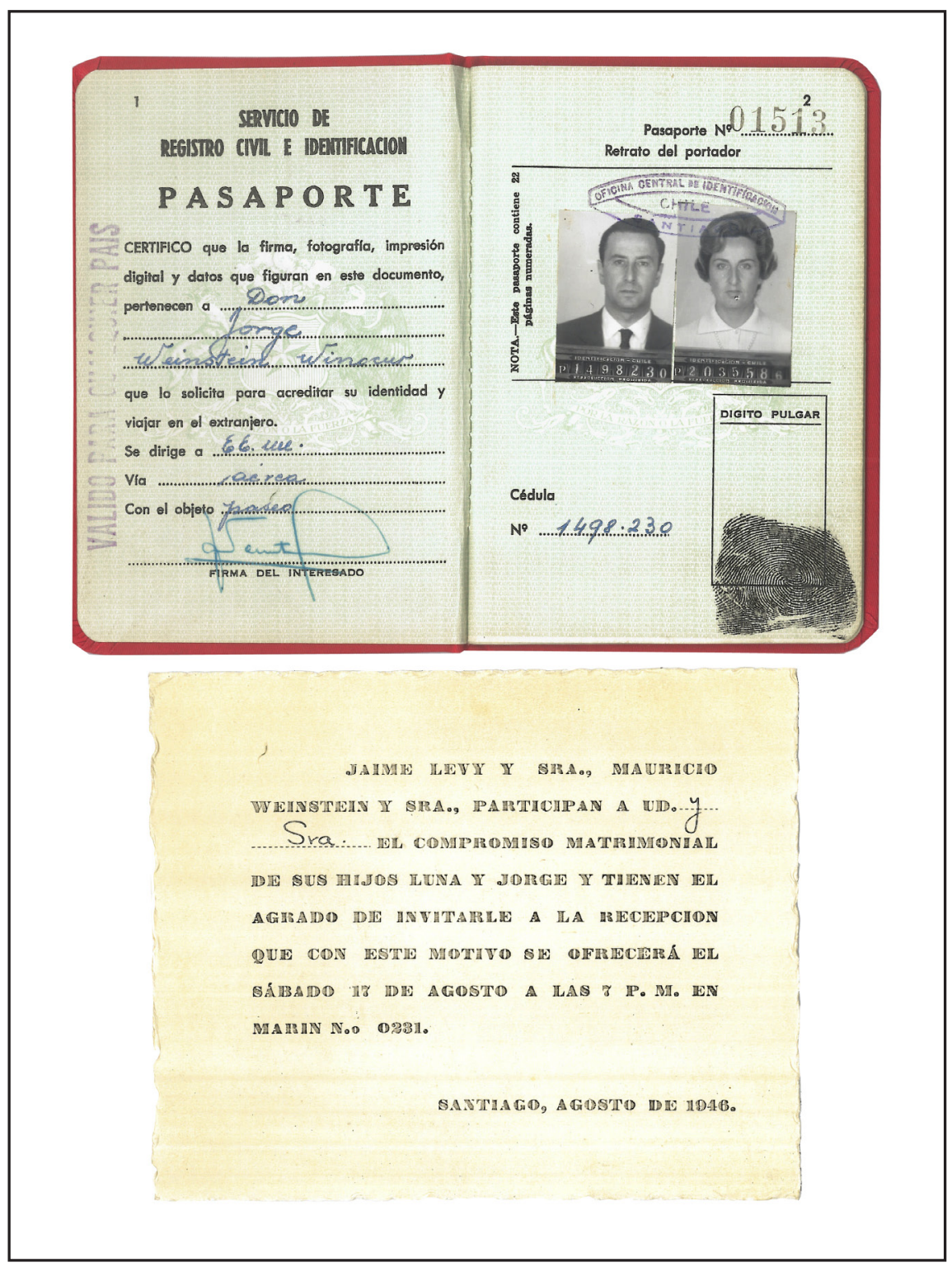

Estoy segura que mi papá quisiera ser recordado antes que nada, como Institutano e Ingeniero Civil, transitando del Instituto Nacional a la Universidad de Chile. Sus años como estudiante universitario, entre 1940 y 1945, coincidieron exactamente con la Segunda Guerra Mundial cuyo horror y sufrimiento lo marcaron profundamente, en particular lo que él consideraba el acontecimiento más trágico y desafiante de nuestro tiempo: el Holocausto del pueblo judío. En su etapa de adulto joven se vinculó al Partido Radical, en el cual militó durante algunos años. Su actividad laboral estuvo dirigida al comercio y la construcción, en sociedad con su padre y hermano, y durante varios años trabajó en algunas empresas públicas; de una de ellas guardo un reconocimiento a una importante gestión que realizó. 
Con mucha satisfacción en la Figura 8 incluyo la carta del Inspector General del Instituto Nacional dirigida a mi abuelo, cuando mi padre estaba egresando de la educación media en el año 1939, la cual incluye un reconocimiento académico y a sus cualidades personales, siendo la más alta distinción que puede concederse a un alumno.

\section{Figura 8}

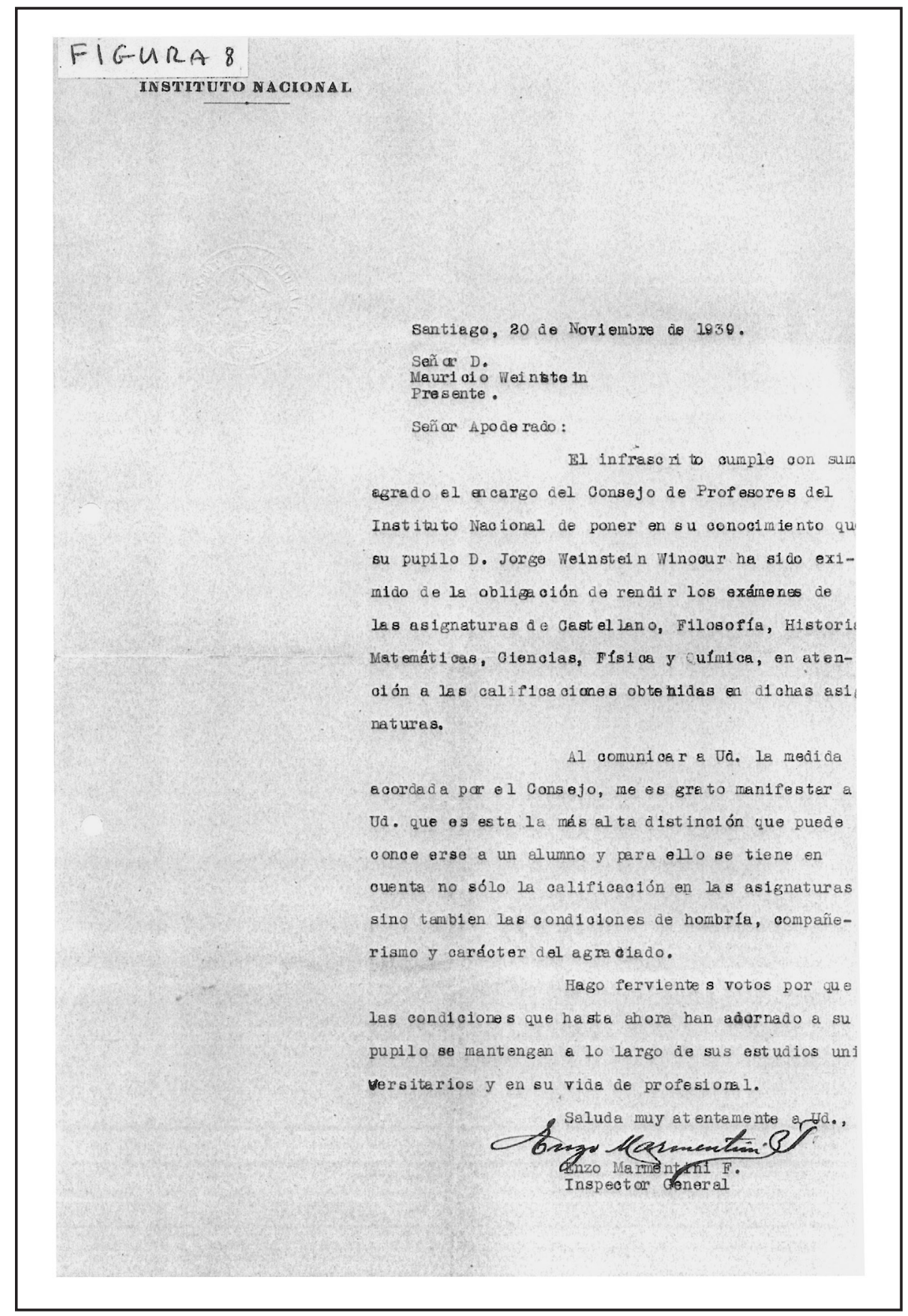


Las grandes pasiones de mi papá fueron su mujer y la música clásica. Fue amante de Mozart y admiraba al gran violinista Heifetz; también fue devoto de Einstein, su fotografía siempre presidió el escritorio de la casa. Junto a un grupo de amigos tuvo la gran "volada" de crear un cuarteto de cuerdas en la década del 50 -llamado Vitacura- donde fue el primer violín, y a través del cual convocaron durante varios años a veladas musicales a amigos y parientes. De esta forma cultivaron su pasión por la música, pero por sobre todo se divirtieron. Este conjunto tan animado fue lamentablemente trizado de manera irreparable a raíz del golpe militar de 1973 y el período de dictadura que le siguió, ya que nunca más volvieron a reunirse y los lazos amistosos terminaron por diluirse. La opción de mis padres fue la democrática.

Mi mamá fue alguien muy especial que dejó recuerdos imborrables en muchas personas por su generosidad, sensibilidad y carisma. Falleció de poco más de sesenta años de un agresivo cáncer mamario, cuando todavía los tratamientos para esta enfermedad eran incipientes. Desde entonces la sensación de orfandad me ha acompañada siempre. Fue lúcida, bonita, inquieta, actualizada a perpetuidad, tanto como una extraordinaria y reconocida anfitriona. De adulta mayor se destacó en el bridge, como en muchos otros aspectos a lo largo de su vida.

Fortalecida por una muy buena educación escolar y siendo una lectora obsesiva, se transformó en una gran estudiosa y eximia conocedora de lenguas y literatura. Su inclinación por la poesía era evidente y Neruda estuvo entre sus predilectos. Entre otros autores, fue una experta en Shakespeare, llegó a ser una profunda conocedora de toda su obra, la cual continuamente recitaba en su idioma original. De esta forma fue adquiriendo un nivel intelectual superior.

Reconozco que yo sentí fascinación por mi mamá, y entre mis pecados ocultos está el haber sido su espía: de los libros que leía, de sus cajones, su ropa, sus desplazamientos, sus conversaciones. ¡Qué privilegio haber sido su hija y cuánto amor me dio! Como tributo, dos de sus bisnietas llevan su nombre, que era también el de su abuela paterna. Ojalá esta tradición se vaya repitiendo a lo largo de las próximas generaciones. 
A mis padres los escuché en varias oportunidades citar en inglés la siguiente frase, cuyo origen desconozco, y que al repetirla recupero nuevamente en mi conciencia su corporalidad: let the bygone be bygone, savor the present, and allow the future to take care of itself (deja que el pasado quede en el pasado, saborea el presente y permite que el futuro se hago cargo de si mismo).

Los visualizo a ambos muy arraigados en el siglo que les tocó vivir. Liberales, tolerantes y abiertos a los cambios, fueron adquiriendo una postura progresista frente a los acontecimientos de su entorno y el mundo. En este sentido, creo que su identidad fue más cosmopolita que judía; ¿es que se contraponen en la era de la globalización, me pregunto? Analizando el comportamiento de los intelectuales judíos en la Europa pre-II Guerra Mundial, Sznaider (2012) plantea que a través de la integración ellos buscaron extender sus fronteras más allá de sus condiciones particulares, en la medida que estando inmersos en una sola cultura podía ser limitante. Estimo que esta línea de argumentación se aplica perfectamente a la conducta de mis padres: por su propia voluntad se unieron a otros grupos de referencia que fueron sobreponiéndose a su grupo de origen (la comunidad judía donde nacieron). Si bien los lazos con esta última se debilitaron su pertenencia a ella nunca estuvo en cuestión, lo que se expresó por ejemplo, en que siguieron siendo socios de algunas organizaciones y también, apoyando la causa de Israel.

El tema de la diversidad y pluralidad judía es apasionante, existiendo indicios que estos rasgos son ancestrales. El autor Sznaider antes citado, pone en relieve que la cultura judía de la Diáspora siempre se mezcló con otras, siendo por tanto, heterogénea y abierta al exterior. Por su parte, la profesora Roitman (2009) plantea que la complejidad que adquieren las relaciones sociales con el proceso de modernización confronta a las personas con una multiplicidad de posibilidades de elección, siendo imposible que permanezcan atadas a un sistema único de referencias. Ello sin duda acentúa la heterogeneidad, desafía a las minorías en general, y abre espacio a nuevas formas de vivir y experimentar el judaísmo (Roitman, 2008). Este contexto favorece el surgimiento de nuevas identidades, proceso que investiga el profesor Caro (2008), quien hace el contrapunto entre lo que para él son nuevas formas de vivir el judaísmo -donde tienen cabida expresiones y organizaciones que acogen estilos, gustos y opciones diversas- con la revalorización de la ortodoxia religiosa especialmente en los jóvenes. 
De esta forma, termino con preguntas que no puedo responder. ¿Representó la forma de vivir el judaísmo de mis padres un proceso de asimilación? ¿O más bien fue una expresión de la diversidad y pluralidad judía? Me pregunto también si estas interrogantes tienen respuesta, o si no son parte del eterno dilema del ser o no ser judío.

\section{ANEXO:}

\section{Arbol Genealógico Familia Weinstein Levy}

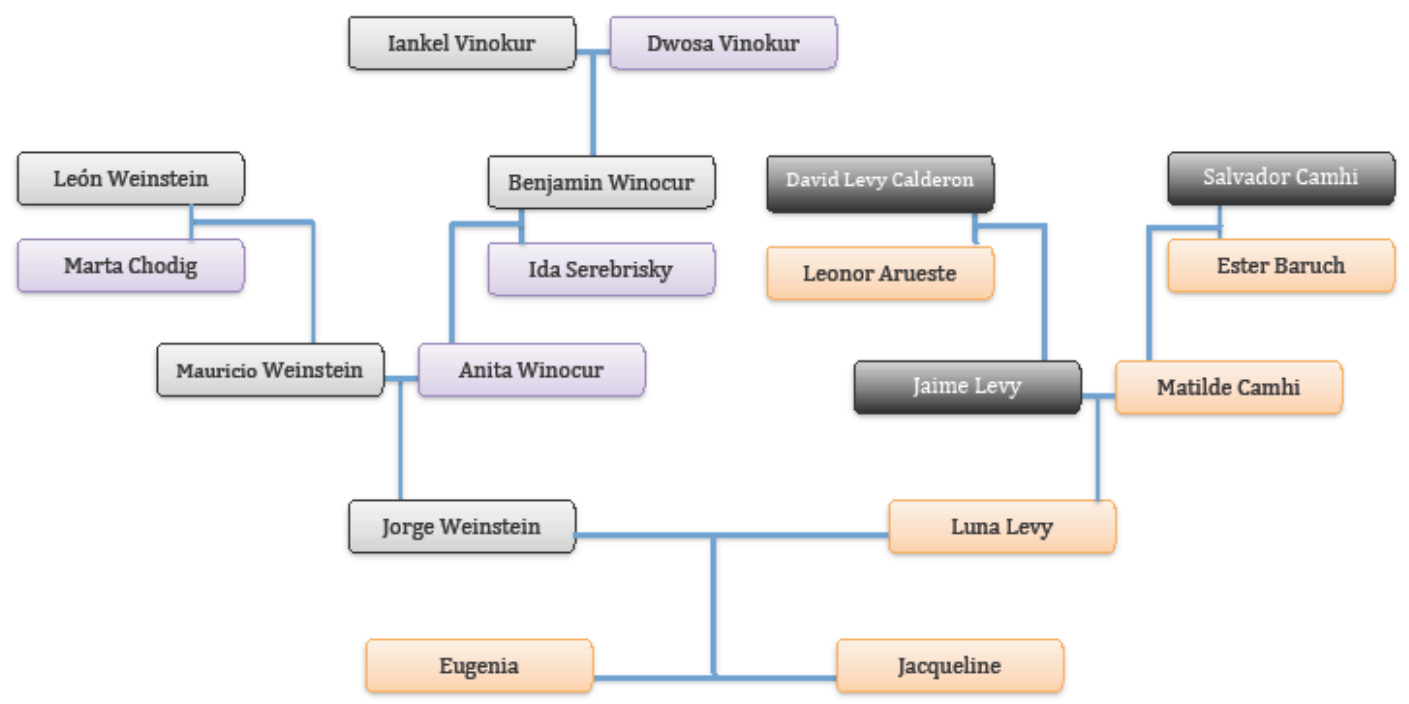




\section{BIBLIOGRAFÍA}

ARENDT, Hannah. Escritos Judíos. Edición a cargo de Jerome Kohn y Ron H. Feldman, traducción de Eduardo Cañas, Barcelona, Paidós, 2009. 704 páginas

ARMONY, Paul. "Moisesville: la colonia pionera judía". Revista TOLDOT № 4 (sin número de páginas), Asociación de Genealogía Judía de la Argentina, julio 1997.

CAMPOS, Juana Lorena. "Margo Glantz: judía, mexicana y rusa". Cuaderno Judaico № 25, pp. 55-72, Centro de Estudios Judaicos, Facultad de Filosofía y Humanidades, Universidad de Chile, diciembre 2008.

CARO, Isaac. "Identidades judías contemporáneas en América Latina”. Atenea № 497, pp. 79.93, Universidad de Concepción, I Sem. 2008.

COHEN, Jacob. Los judíos en Temuco. 100 años de historia. El inicio de la comunidad sefaradí en Chile. Santiago de Chile, RIL Editores, 2002. 290 páginas

FINGUERET, Manuela. $\underline{\text { Hija del Silencio. }}$ Buenos Aires, Planeta Booket, 2006. 201 páginas

FLIER, Patricia. Investigación en curso sobre la inmigración judía en la Argentina y la Colonia Clara. Capítulos 4 y 5. Universidad Nacional de La Plata, Argentina, 2012.

GERCHUNOFF, Alberto. Los Gauchos Judíos. Editorial Universitaria de Buenos Aires, 1964. 119 páginas

GURALNIK, Sonia. Para siempre en mi memoria. Santiago de Chile, Ediciones B Grupo Zeta, 2000. 165 páginas

MASSMANN, Stefanie. "Arbol genealógico y álbum de familia: dos figuras de la memoria en relatos de inmigrantes judíos". Estudios filológicos $N^{\circ} 40$, pp. 131-137, Facultad de Filosofía y Humanidades, Universidad Austral de Chile, septiembre 2005.

MARTINEZ PARDO, Marta Judith. "HANNAH ARENDT, Escritos Judíos, edición a cargo de Jerome Kohn y Ron H. Feldman, traducción de Eduardo Cañas, Paidós, Barcelona, 2009. 704 páginas". Foro Interno 9, pp. 193-196, sección Crítica de Libros, pp. 181-256, Universidad Complutense de Madrid, 2009.

MATUS, Mario. Tradición y Adaptación: Vivencia de los Sefardíes en Chile. Santiago de Chile, Universidad de Chile, Facultad de Filosofía y Humanidades, Departamento de Ciencias Históricas; Comunidad Israelita Sefaradí de Chile, 1993. 215 páginas

MENDELSON, Jose - Rapaport, Nicolas - Gerchunoff, Alberto - Weill, Simon - Kaplan, Isaac - Efron, Jedida - Merkin, Moises. 50 años de colonización judía en la Argentina, Buenos Aires, Delegación de Asociaciones Israelitas Argentinas, 1939. 315 páginas

MÉTTER, IZRAíL. Genealogía y otros relatos. Traducción de Ricardo San Vicente, Barcelona, Editorial Lumen, 2001. 173 páginas

RIMSKY, Cynthia. Poste Restante. Santiago de Chile, Editorial Sudamericana, 2001. 193 páginas

ROITMAN, Deborah. "Identificadores judíos y su manifestación en el judaísmo latinoamericano". Cuaderno Judaico $N^{\circ} 25$, pp.175-202, Centro de Estudios Judaicos, Facultad de Filosofía y Humanidades, Universidad de Chile, diciembre 2008. 
ROITMAN, Deborah. "Integrando vocablos: identidad y extranjero. El caso de los hispanos en Estados Unidos". Cuaderno Judaico № 26, pp. 1-6, Centro de Estudios Judaicos, Facultad de Filosofía y Humanidades, Universidad de Chile, diciembre 2009.

SZNAIDER, Natan. La memoria judía y el orden cosmopolita. Traducción de Agustín Cosovschi, Buenos Aires, Capital Intelectual, 2012. 307 páginas

YERUSHALMI, Yosef Hayim. Zajor: la historia judía y la memoria judía. Traducción de Ana Castaño y Patricia Villaseñor, Barcelona, Antropos Editorial; México, Fundación Cultural Eduardo Cohen, 2002. 153 páginas 